\title{
THE PRIMARY STRUCTURE OF NOXIUSTOXIN: A K+ CHANNEL BLOCKING PEPTIDE, PURIFIED FROM THE VENOM OF THE SCORPION CENTRUROIDES NOXIUS HOFFMANN
}

\author{
by \\ LOURIVAL DOMINGOS POSSANI \\ Departamento de Biologia Molecular, Instituto de Investigaciones Biomédicas -UNAM \\ Apartado Postal 70-274, Delegación Coyoacán 04510 \\ México, D.F., Mexico \\ and \\ BRIAN M. MARTIN \\ Max-Planck-Institut für Ernährungsphysiologie, Rheinlanddamm 201 \\ D-4600 Dortmund, FRG \\ Present address: Department of Biochemistry, University of Massachusetts Medical Centre \\ 55 Lake Avenue, N. Worcester, MA 01605, USA \\ and \\ IB SVENDSEN \\ Department of Chemistry, Carlsberg Laboratory, \\ Gamle Carlsberg Vej 10, DK-2500 Copenhagen Valby
}

Keywords: Scorpion toxins, Centruroides noxius, Tityus serrulatus, amino acid analysis,
amino acid sequence, primary structure, sequence homology

Noxiustoxin, component II-11 from the venom of scorpion Centruroides noxius HofFMANN, was obtained in pure form after fractionation by Sephadex G-50 chromatography followed by ion exchange separation on carboxymethylcellulose columns (17). The primary structure of Noxiustoxin, a polypeptide 39 amino acid residues long was determined by automatic EDMAN degradation and chemical cleavage with cyanogen bromide followed by amino acid analysis of the two resulting peptides. Its sequence is: Thr-Ile-Ile-Asn-Val-Lys-Cys-Thr-Ser-Pro-Lys-GlnCys-Ser-Lys-Pro-Cys-Lys-Glu-Leu-Tyr-Gly-Ser-Ser-Ala-Gly-Ala-Lys-Cys-Met-Asn-Gly-Lys-Cys-Lys-Cys-TyrAsx-Asn, with a molecular weight of $4,184 \pm 6$. No histidine, arginine, tryptophan or phenylalanine was found. Noxiustoxin is the first short toxin directed against mammals and the first $\mathrm{K}^{+}$channel blocking polypeptide-toxin (4) found in scorpion venoms. 


\section{INTRODUCTION}

Until recently, the great majority of the scorpion toxins were known to be polypeptides with molecular weights in the order of 7,000 , composed of 57 to 66 amino acid residues cross-linked by four disulphide bridges $(1,12,17,21)$ with a specificity directed towards the sodium channel $(3,6,7,8,10,13,15)$. These toxins bind to excitable membranes only when the membrane is polarized (6). The presence of a potential difference across membranes from axons, ganglions, nerve ending terminals (synaptosomes), neuroblastoma cells, etc., is a requirement for binding to the $\mathrm{Na}^{+}$channels. A second type of scorpion toxin called $\beta$-toxin has been proposed recently (7). This type of toxin is until now represented by only one toxin purified from the venom of the Mexican scorpion Centruroides suffusus suffusus, and binds to rat brain synaptosomes independent of polarization (11).

More recently, physiological experiments, on the squid giant axon, conducted with purified toxins from another Mexican scorpion Centruroides noxius (4) have suggested that there are several types of toxins. One of these, binds to the sodium channel and the other to the potassium channel, both binding effects are independent of the applied voltage and are fully reversible. In the same venom we have purified a third toxin that binds to synaptosomal membranes and a fourth toxin that affects specifically the neuromuscular system of crustaceans e.g. crayfish and crab (Possani and Mochca-Morales, unpublished observations).

In this communication we present the chemical characterization of the potassium channel blocking toxin, for which we propose the name: Noxiustoxin.

\section{MATERIALS AND METHODS}

\subsection{Materials and lethality tests}

The collection of scorpions from Nayarit, Mexico, the preparation of the soluble venom, the chromatographic resins, the reagents and solvents were all the same as previously described (17). Similarly the lethality of the different fractions and pure toxins were followed according to our previous publication (17).

\subsection{Purification of Noxiustoxin}

The sample used for sequencing was obtained from the three peak-tubes of fraction 11 from Figure 2 of the preceeding publication (17). Actually this material was a common pool from two independent runs. The side-tubes from fraction II-11 (Figure 2 ref. 17) still contain small contaminants, as verified by polyacrylamide gel electrophoresis in the acetate-urea- $\beta$-alanine system of REISFELD et al. (19). The electrophoretic mobility of Noxiustoxin in this system is practically the same as the tracking dye: Pyronin Y. In order to use the entire fraction 11 for chemical and biological studies a third purification step was introduced, which consists in a carboxymethylcellulose column equilibrated with $50 \mathrm{~mm}$-sodium phosphate buffer, $\mathrm{pH} 6.0$. The column $(0.9 \times 30$ $\mathrm{cm}$ ) was eluted with a linear gradient of $\mathrm{NaCl}$ from 0 to $0.38 \mathrm{M}$, giving a major component (Noxiustoxin) with small contaminant components (L.D.Possant and J. MochCa-Morales, unpublished observations). The homogeneity of Noxiustoxin was verified by gel electrophoresis (19) and by amino acid sequencing.

\subsection{Reduction and carboxymethylation}

Reduction and alkylation with iodo[2${ }^{14} \mathrm{C}$ ]acetic acid was done as described previously for other toxins (18). The RCM-toxin was chromatographed on a Sephadex G-50 $(2.5 \times 120 \mathrm{~cm})$ column. The material eluting at 195 to $230 \mathrm{ml}$ was lyophilized and used directly for amino acid and sequence analyses.

\subsection{Amino acid analysis and sequence determination}

Two samples of RCM-toxin were hydrolyzed in $5.8 \mathrm{M}-\mathrm{HCl}$ at $110^{\circ} \mathrm{C}$ in vacuo for 24 and 48 hours and analysed using a Durrum D-500 analyzer as described (18). A third sample of unreduced Noxiustoxin was hydrolyzed in the presence of methanesulfonic acid by the technique of PENke et al. (16) in order to determine a possible tryptophan content, and analyzed as above.

The methodology followed for automated EDMAN degradation and identification of the derivatized PTH-amino acids was identical to the procedure described previously $(9,17,18,22)$. 


\subsection{Cyanogen bromide cleavage and carboxypep- tidase treatment}

Due to the presence of a methionine residue in the molecule, the reduced and carboxymethylated Noxiustoxin could be cleaved by cyanogen bromide. An 8 fold excess of cyanogen bromide over toxin $(w / w)$ in $70 \%$ formic acid was used according to the technique described (2). The products were separated on the same Sephadex G-50 column used for purification of the RCMtoxin (section 2.3).

Carboxypeptidase $\mathrm{Y}$ treatment was performed as described previously (14).

\section{RESULTS AND DISCUSSION}

The amino acid composition of Noxiustoxin was shown to be: 4 Asp, 2 Thr, 4 Ser, 2 Glu, 2 Pro, 3 Gly, 2 Ala, 1 Val, 1 Met, 2 Ile, 1 Leu, 2 Tyr, 7 Lys and 6 Half-Cys. Amino acid analyses performed on samples hydrolyzed in methanesulfonic acid (16) revealed the absence of Trp. All together there are only 39 amino acid residues with a calculated molecular weight of 4,184 \pm 6 , and without histidine, arginine, tryptophan or phenylalanine. These data show that Noxiustoxin is the smallest toxin active towards mammals purified to date. The only other known small toxin from the venom of scorpions is the insect toxin Be IT, mentioned by RochaT et al. (21). It is worth noting that Noxiustoxin injected intraperitoneally into mice (albino mouse, Mexican strain) at a dose of $20 \mathrm{mg} \cdot \mathrm{kg}^{-1}$ weight is lethal.

Noxiustoxin (100 nmoles) was sequenced from its $\mathrm{N}$-terminal amino acid residue up to and including residue 37 . The repetitive yield obtained from the sequencer was $96 \%$ up to residue 34 . The three last amino acid residues were recovered in much lower yields and after residue 37 no amino acids were obtained, probably due to the loss of the remaining dipeptide during the organic washes. The sequence determined is shown in Figure 1. The position of the last two amino acid residues at the C-terminal end were inferred from the amino acid analysis, which shows the presence of four aspartic acid residues, only two of which were located by direct sequencing. However, treatment of Noxiustoxin with carboxypeptidase $\mathrm{Y}(14)$ for $90 \mathrm{~min}$ using an enzyme to substrate ratio of 1:20 liberated no aspartic acid and only small amounts of asparagine. No free asparagine was present before enzyme treatment.

The presence of methionine at position 30 permitted the cleavage of Noxiustoxin by cyanogen bromide treatment. Two main peptides were obtained after gel filtration on Sephadex G-50 (figure not shown). The first eluted peptide (higher molecular weight) revealed the amino acid composition expected from the $\mathrm{N}$-terminal sequence data. The second peptide, when analysed gave the amino acid composition expected for the Cterminal peptide containing: CM-cysteine, aspartic acid, glycine, tyrosine and lysine, although the integer numbers obtained for lysine, aspartic acid and CM-cysteine were low compared to the values expected, possibly due to incomplete derivatization of cysteines and partial alkylation of lysine by radioactive iodo-acetic acid. The latter observation is also based on radioactive measurements obtained on amino acid residue 35 , during the automatic sequencing. The number of counts obtained for residue 35 were higher than expected from the normal overlapping due to incomplete cleavage in the automatic sequencer, although the identification by HPLC clearly indicated the presence of lysine at position 35 . This result is compatible with a small ${ }^{14} \mathrm{C}$-carboxymethylation of lysine 35 . No other amino acid residues were found in the short peptide, so the possibility of a "normal" size neurotoxin (57-66 amino acid residues long) is completely ruled out. All these data combined, made possible the determination of the primary structure of the short toxin shown in Figure 1, except for residue 38 that could be aspartic acid or asparagine. Since

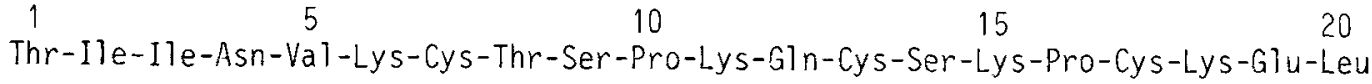

$$
\begin{aligned}
& 25 \\
& \text { Tyr-Gly-Ser-Ser-Ala-Gly-Ala-Lys-Cys-Met-Asn-Gly-Lys-Cys-Lys-Cys-Tyr-Asx-Asn }
\end{aligned}
$$

Figure 1. The amino acid sequence of Noxiustoxin. 
Noxiustoxin have only six half-cystines and we have no indication of the presence of free thiol groups, we assume that it has only three disulphide bridges instead of four like all the scorpion toxins studied so far. In conclusion, Noxiustoxin is the first polypeptide toxin shown to be specific for potassium channels (14); the first example of a short peptide chain scorpion toxin directed against mammals, and it has a completely different amino acid sequence, when compared with sequences of more than 39 purified toxins $(17,18,20,21)$ known to be present in purified toxins from the venom of scorpions from all over the world.

$\mathrm{A} \mathrm{K}^{+}$channel blocking toxin from $\mathrm{C}$. noxius which is homologuos with Noxiustoxin has been isolated as a minor component of peak II-10 (Figure 2 , ref. 17). Due to the very small quantity in which this toxin is present it has only been possible to determine the $\mathrm{N}$-terminal amino acid sequence for 15 cycles which, however, was enough to demonstrate the homology with Noxiustoxin (Figure 2).

$\mathrm{K}^{+}$channel blocking toxins of the Noxiustoxin-type are not confined to $C$. noxius. In a previous publication (18) we have described the purification of a series of toxins from Tityus serrulatus Lutz and Mello. Rechromatography of peak II-9 (Figure 2, ref. 18) on CM-cellulose followed by amino acid sequencing revealed two peptides one of which had an already known sequence (III-8, Figure 3, ref. 18) which has no blocking effect on the $\mathrm{K}^{+}$channel of the squid giant axon (E. Carbone, G. Prestipino, L.D. Possani, unpublished observation). The other peptide ( $50 \%$ of total) had a sequence which is homologous with that of Noxiustoxin (Figure 2). The toxin represents less than one per cent of the total amount of toxins in the venom of T. serrulatus. Because of the sequence homology with Noxiustoxin, peak II-9 (18) was tested on the squid giant axon and shown to have a strong inhibitory effect on the $\mathrm{K}^{+}$channel and none or very little on the $\mathrm{Na}^{+}$channel (see toxin 1 from $\mathrm{T}$. serrulatus in ref. 5). The findings discussed above indicate that toxins related to Noxiustoxin are expected to be found universally among the scorpions, although they have not yet been isolated due to their presence in minute amounts.

\section{ACKNOWLEDGEMENTS}

The authors wish to thank Professor M. OTTESEN of the Carlsberg Laboratory for allowing us the use of the sequencer facilities and Professor A. MaElicke from the Max-Planck-Institute, Dortmund for supporting part of this work during the sabbatical leave of L.D.P., with a fellowship of the Humboldt Foundation. The excellent technical assistance of Mrs. BodIL CORNELIUSSEN and LONE SøRENSEN is gratefully acknowledged. The project was partially granted by the Mexican Consejo Nacional de Ciencia y Tecnologia (PCCBBNA 001370).

\section{REFERENCES}

1. Babin, D.R., D.D. WaTt, S.M. Goos \& R.V. MLEJNEK: Amino acid sequences of neurotoxic protein variants from the venom of Centruroides sculpturatus Ewing. Arch. Biochem. Biophys. 164, 694-706 (1974)

$$
\begin{aligned}
& \text { I I-9 } \\
& \text { NXT } \\
& \text { II }-10-2
\end{aligned}
$$

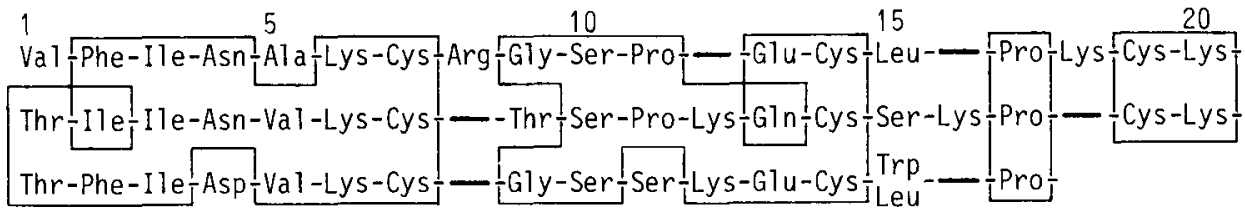

$$
\begin{aligned}
& \text { I I-9 } \\
& \text { NXT }
\end{aligned}
$$

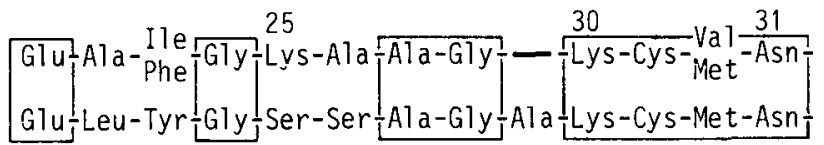

Figure 2. Comparison of the $\mathrm{N}$-terminal amino acid sequences of $\mathrm{K}^{+}$channel blocking toxin II. 9 from T. serrulatus with toxins II.10 and Noxiustoxin from C. noxius.

Half-cystines have been aligned and gaps are introduced to maximize homology. The numbering system for the sequences has been adapted accordingly. Residues which are invariant in the toxins are boxed. Positions with two amino acid residues indicate uncertainty in the sequence. NXT $=$ Noxiustoxin. 
2. Biedermann, K., U. Montali, B. Martin, I. SVENDSEN \& M. OTTESEN: The amino acid sequence of proteinase A inhibitor 3 from baker's yeast. Carlsberg Res. Commun. 45, 225-235 (1980)

3. Cahalan, M.D.: Modification of sodium channel gating by scorpion venom. J. Physiol. London 244, 511-534 (1975)

4. Carbone, E., E. Wanke, G. Prestipino, L.D. Possani \& A. Maelicke: Selective blockage of voltage-dependent $\mathrm{K}^{+}$channels by a novel scorpion toxin. Nature, London 296, 90-91 (1982)

5. Carbone, E., G. Prestipino, E. Wanke, L.D. Possani \& A. Maelicke: Selective action of scorpion neurotoxins on the ionic currents of the squid giant axon. Proceedings from the 7 th World Congress on Animal, Plant and Microbial Toxins, Brisbane, Australia, July (1982) to be published by Toxicon

6. Catterall, W.A.: Neurotoxins that act on voltage-sensitive sodium channels in excitable membranes. Ann. Rev. Pharmacol. Toxicol. 20, 15-43 (1980)

7. Couraud, F., E. Jover, J.M. Dubois \& H. Rochat: Two types of scorpion toxin receptor sites, one related to the activation, the other to the inactivation of the action potential sodium channel. Toxicon 20, 9-16 (1982)

8. Couraud, F., H. Rochat \& S. Lissitzky: Binding of scorpion neurotoxins to chick embryonic heart cells in culture and relationship to calcium uptake and membrane potential. Biochemistry 19, 457-462 (1980)

9. EDMAN, P. \& G. BEGG: A protein sequenator. Eur. J. Biochem. I, 80-91 (1967)

10. Gillespie, J.I. \& H. Meves: The effect of scorpion venoms on the sodium currents of the squid giant axon. J. Physiol. London 308, 479 499 (1980)

11. Jover, E., F. Couraud \& H. Rochat: Two types of scorpion neurotoxins characterized by their binding to two separate receptor sites on rat brain synaptosomes. Biochem. Biophys. Res. Commun. 95, 1607-1614 (1980)

12. Kopeyan, C., G. Martinez, S. Lissitzky, F. Miranda \& H. Rochat: Disulphide bonds of toxin II of the scorpion Androctonus australis Hector. Eur. J. Biochem. 47, 483-489 (1974)

13. Krueger, B.K., M. Blaustein \& R.W. RATZlAFF: Sodium channels in presynaptic nerve terminals. Regulation by neurotoxin. J. Gen. Physiol. 76, 287-313 (1980)

14. Martin, B., I. Svendsen \& M. Ottesen: Use of carboxypeptidase $Y$ for carboxy-terminal sequence determination in proteins. Carlsberg Res. Commun. 42, 99-102 (1977)

15. NONNER, W.: Effects of Leiurus scorpion venom on the "gating" current in myelinated nerve. Adv. in Cytopharmacol. 3, 345-352 (1979)

16. Penke, B., R. Ferenczi \& K. Kovács: A new acid hydrolysis method for determining tryptophan in peptides and proteins. Anal. Biochem. 60, 45-50 (1974)

17. Possani, L.D., M.A.R. Dent, B.M. Martin, A. Maelicke \& I. Svendsen: The amino terminal sequence of several toxins from the venom of the Mexican scorpion Centruroides noxius Hoffmann. Carlsberg Res. Commun. 46, 207-214 (1981)

18. Possani, L.D., B.M. Martin, J. MochcaMorales \& I. Svendsen: Purification and chemical characterization of the major toxins from the venom of the Brazilian scorpion Tityus serrulatus Lutz and Mello. Carisberg Res. Commun. 46, 195-205 (1981)

19. Reisfeld, R.A., U.J. Lewis \& D.E. Williams: Disk electrophoresis of basic proteins and peptides on polyacrylamide gels. Nature, London 195, 281-283 (1962)

20. Rochat, H (ED.): Proceedings of the 4th European Symposium on Animal, Plant and Microbial Toxins. Marseille (France) June 1981, published in Toxicon, 20 (1) 1-367 (1982)

21. Rochat, H., P. Bernard \& F. Couraud; Scorpion toxins: Chemistry and mode of action. Adv. Cytopharm. 3, 325-334 (1979)

22. TARR, G.E., J.F. BeEcher, M. BELl \& D.J. MCKeAN: Polyquaternary amines prevent peptide loss from sequenators. Anal. Biochem. 84 , 622-627 (1978) 